\title{
Evaluation of sleep in women with menopause: results of the Pittsburg Sleep Quality Index and polysomnography
}

\author{
Kağan Ağan ${ }^{1}$, Recep Özmerdivenli ${ }^{1}$, Yıldız Değirmenci², Mete Çağlar ${ }^{3}$, Alper Başbuğ ${ }^{3}$, Ege Güleç Balbay ${ }^{4}$, \\ Mehmet Ali Sungur ${ }^{5}$ \\ ${ }^{1}$ Department of Physiology, Düzce University Faculty of Medicine, Düzce, Turkey \\ ${ }^{2}$ Department of Neurology, Düzce University Faculty of Medicine, Düzce, Turkey \\ ${ }^{3}$ Department of Gynecology and Obstetrics, Düzce University Faculty of Medicine, Düzce, Turkey \\ ${ }^{4}$ Department of Chest Disease, Düzce University Faculty of Medicine, Düzce, Turkey \\ ${ }^{5}$ Department of Biostatistics and Medical Informatics, Düzce University Faculty of Medicine, Düzce, Turkey
}

\section{Abstract}

Objective: To investigate subjective sleep quality among women in the menopausal period and to confirm and diagnose the possible sleep disturbances with polysomnographic (PSG) evaluation objectively.

Material and Methods: Sixty-seven women with menopause were enrolled in the study. Sociodemographic characteristics and the features of menopause were recorded. We assessed subjective sleep quality with Pittsburg Sleep Quality Index (PSQI). To confirm sleep disturbances and further diagnose the underlying cause, PSG evaluation was performed to women with PSQI scores of $>5$ who gave their approval.

Results: Mean PSQI score of women with normal PSG evaluation was $12.00 \pm 3.16$, while it was $11.00 \pm 2.32$ in women with abnormal PSG evaluation $(\mathrm{p}=0.466) ; 59.7 \%(\mathrm{n}=40)$ of women had poor sleep quality. Among these, $11(64.7 \%)$ had abnormal results in the PSG evaluation and were diagnosed with obstructive sleep apnea syndrome (OSAS); $54.5 \%$ had mild OSAS, $27.3 \%$ had moderate, and $18.2 \%$ had severe OSAS. Conclusion: PSQI and PSG evaluations would give a chance to demonstrate sleep problems and shed a light on treatment options according to the underlying causes of sleep disturbances in menopause. (J Turk Ger Gynecol Assoc 2015; 16: 149-52)

Keywords: Menopause, sleep disturbance, Pittsburg Sleep Quality Index, polysomnography

Received: 27 April, 2015

Accepted: 07 June, 2015

Available Online Date: 14 July, 2015

\section{Introduction}

Menopause is the perpetual cessation of menstruation resulting from the loss of ovarian hormonal activity. It is a retrospective diagnosis, which can be detected after 12 months from the last menstruation without any attributable cause. However, surgical menopause is determined as the cessation of menses because of hysterectomy with or without oophorectomy (1). The ovarian failure process is an ongoing period in midlife women, characterized with a change in intermenstrual period and bleeding pattern, accompanied by hormonal fluctuations defined as menopausal transmission or perimenopause that occurs at an average age of 47 years (2).

This period of menopausal transmission may lead to a variety of symptoms because of the changes in blood sex hormone levels, including vasomotor symptoms as hot flashes and night sweats, physical symptoms as headaches, palpitations, bone and joint pains, asthenia, tiredness, sexual concerns because of vaginal dryness, urinary incontinence, depressed mood, and sleep disturbances (3).
Regarding this wide range of symptoms that women may experience in the menopausal period, sleep disturbance is one of the most distressing symptoms affecting $46 \%$ of women between the ages of 40 and 54 years, and $48 \%$ of them at the age of 55-64 years, according to a national sleep foundation survey held in 2007 (4).

Although the previous studies revealed perceived sleep problems more frequently among women with menopause, objective measures of sleep patterns demonstrated that peri- and postmenopausal periods are not related to sleep disturbances (4).

In the light of the current literature knowledge, we aimed to investigate the subjective sleep quality among women in the menopausal period and to confirm and diagnose the possible sleep disturbances with polysomnographic (PSG) evaluation objectively.

\section{Material and Methods}

Patients who were diagnosed with menopause in the Gynecology and Obstetrics outpatient clinics of our university 
and at our city's State Hospital were enrolled in the study between January 2014 and November 2014. Menopause, as a retrospective diagnosis, was determined as the perpetual cessation of menstruation with 12 months of amenorrhea because of the loss of ovarian hormonal activity without other underlying reasons (5). Before enrolment, the content of the study was explained to the patients and written approvals with an informed consent were gathered from them. The local ethical committee of the Düzce University School of Medicine approved the study.

Sociodemographic characteristics of the participants, including the characteristics of menopause, were recorded via face-toface interview with an open questionnaire.

Pittsburgh Sleep Quality Index (PSQI) was used to assess the subjective sleep quality in all patients. This questionnaire is self-rated and evaluates sleep quality and disturbances over a 1-month period. It has 19 individual items with seven "component" scores: subjective dysfunction. The scores of each item of the index vary between 0 and 3 . Total score of these seven components makes one score of $0-21$. A total score $>5$ indicates insufficient sleep quality. PSQI of $\leq 5$ indicates good sleepers, while PSQI of $>5$ corresponds with poor sleepers (6).

Patients with a PSQI of $>5$ and who accepted this noninvasive procedure were referred to the sleep laboratory of our university and underwent an overnight PSG evaluation (Alice 5 Sleep System, Philips, Respironics, Pennsylvania, United States) to confirm the existence of sleep disturbance objectively.

PSG consists of a simultaneous recording of multiple physiological parameters, including electroencephalogram (EEG), electrooculogram (EOG), electromyogram (EMG), electrocardiogram (ECG), oral and nasal air flow cannula, thorax and abdomen movements, body position, snoring, and pulse oxymeter. At least 6 hours overnight PSG records were obtained for each patient. The all-night PSG sleep records were manually scored in a computer program. Apnea was defined as the complete lack of or an airflow reduction of $>90 \%$ through the mouth and nose. Hypopnea scoring criteria defined as an airflow reduction of at least $\geq 30 \%$ for 10 seconds associated with oxygen desaturation of $\geq 3 \%$ or arousal. Apnea-Hypopnea Index (AHI) is represented by the number of apnea and hypopnea events per hour of sleep. Patients with AHI of $\geq 5$ were diagnosed with obstructive sleep apnea syndrome (OSAS). The severity of OSAS was considered as follows: normal (AHI of $<5$ ); mild sleep apnea (AHI of 5-15); moderate sleep apnea (AHI of 16-30); and severe sleep apnea (AHI of >30) (7).

\section{Statistical analysis}

Statistical analyses of data were performed with Predictive Analytics Software (PASW) v.18, which is a registered trademark (SPSS Inc., Chicago, United States). Descriptive statistics were presented as mean \pm standard deviation or median interquartile range (IQR) for continuous variables, and as frequency and percentage for categorical variables. The groups were compared with independent samples t-test or Mann-Whitney U-test. Chisquare or Fisher's exact test was used to assess categorical data based on test assumptions. P values of $<0.05$ were considered statistically significant.

\section{Results}

A total of 67 women with the diagnosis of menopause were enrolled in the study. Mean age was 52.12 \pm 7.24 years (range $=33-72$ years). Mean body mass index (BMI) of the participants were $29.43 \pm 4.81 \mathrm{~kg} / \mathrm{m}^{2}$ (range $=17.63-41.91$ ). Table 1 shows the sociodemographic features of the participants.

Median duration of menopause was 3 years (range $=1.5-8$ years). Among 67 women with menopause, $35.8 \%(n=24)$ were diagnosed with surgical menopause, while $64.2 \%(n=43)$ were diagnosed with natural menopause. In the overall participants, $17.9 \%(n=12)$ women were receiving hormone replacement therapy (HRT). When we assessed the comorbidity in the study group, we found that $11.4 \%(n=11)$ of the women had diabetes mellitus (DM), 35.8\% $(n=24)$ had hypertension (HT), 6\% $(n=4)$ had hypothyroidism, $7.5 \%(n=5)$ had hyperthyroidism, and $47.8 \%(n=32)$ had headaches.

In 67 women with menopause, subjective sleep quality was measured with PSQI, and according to the results of PSQI, $59.7 \%(n=40)$ of the women were found to have poor sleep quality. Poor sleep quality rates were found to be $60.5 \%(n=26)$ in women with natural menopause, and 58.3\% $(n=14)$ in women with surgical menopause. No statistically significant difference was found between the groups $(p=0.865)$.

When we further evaluated the sociodemographic and clinical features of the groups with normal and high PSQI scores, the only statistically significant difference found was in the cigarette smoking group, in which the mean PSQI score was higher among the cigarette smokers, suggesting a poorer sleep quality than nonsmokers $(\mathrm{p}=0.02)$. Table 2 shows the evaluation of PSQI scores with the sociodemographic characteristics of the participants.

Table 1. Sociodemographic features of the participants

\begin{tabular}{|c|c|c|}
\hline & & n (\%) \\
\hline \multirow{3}{*}{ Occupation } & Housewife & $54(80.6)$ \\
\hline & Retired & $5(7.5)$ \\
\hline & Worker & $8(11.9)$ \\
\hline \multirow{3}{*}{ Marital status } & Married & $59(88.1)$ \\
\hline & Single & $2(3.0)$ \\
\hline & Widow & $6(9.0)$ \\
\hline \multirow{5}{*}{ Education } & Literate & $13(19.7)$ \\
\hline & Primary school & $39(59.1)$ \\
\hline & Secondary school & $2(3.0)$ \\
\hline & High school & $9(13.6)$ \\
\hline & University & $3(4.5)$ \\
\hline \multirow{5}{*}{ Daily habits } & Cigarette smoking & $14(21.2)$ \\
\hline & Alcohol use & $3(4.5)$ \\
\hline & Tea consumption & $64(97.0)$ \\
\hline & Coffee consumption & $26(39.4)$ \\
\hline & Chronic drug use & $36(55.4)$ \\
\hline
\end{tabular}

$\mathrm{n}=$ number, $\%=$ percentage 
Table 2. The evaluation of PSQI scores with the sociodemographic characteristics of the participants

\begin{tabular}{|c|c|c|c|}
\hline & $\begin{array}{c}\text { Women with } \\
\text { normal PSQI } \\
\text { scores }(\mathbf{n}=\mathbf{2 7})\end{array}$ & $\begin{array}{c}\text { Women with } \\
\text { abnormal PSQI } \\
\text { scores }(n=40)\end{array}$ & $\mathbf{p}$ \\
\hline Mean Age (year) & $54.19 \pm 7.04$ & $50.73 \pm 7.11$ & 0.054 \\
\hline Mean BMI $\left(\mathrm{kg} / \mathrm{m}^{2}\right)$ & $30.33 \pm 4.99$ & $28.79 \pm 4.63$ & 0.205 \\
\hline $\begin{array}{l}\text { Mean duration of } \\
\text { menopause (year) }\end{array}$ & $3(1.5-12)$ & $3(1.5-8)$ & 0.738 \\
\hline Surgical menopause & $10(37.0)$ & $14(35.0)$ & 0.865 \\
\hline HRT & $5(18.5)$ & $7(17.5)$ & 0.915 \\
\hline $\mathrm{DM}$ & $3(11.1)$ & $8(20.0)$ & 0.504 \\
\hline HT & $11(40.7)$ & $13(32.5)$ & 0.490 \\
\hline Hypothyroidism & $1(3.7)$ & $3(7.5)$ & 0.643 \\
\hline Hyperthyroidism & $2(7.4)$ & $3(7.5)$ & 0.999 \\
\hline Headache & $11(40.7)$ & $21(52.5)$ & 0.345 \\
\hline Cigarette smoking & $2(7.4)$ & $12(30.8)$ & 0.022 \\
\hline Alcohol use & $0(0.0)$ & $3(7.5)$ & 0.267 \\
\hline Tea consumption & $27(100.0)$ & $37(94.9)$ & 0.509 \\
\hline Coffee consumption & $12(44.4)$ & $14(35.9)$ & 0.485 \\
\hline Drug use & $15(55.6)$ & $21(55.3)$ & 0.981 \\
\hline \multicolumn{4}{|c|}{$\begin{array}{l}\text { *Continuous variables are defined as mean } \pm \text { standard deviation or } \\
\text { median interquartile range (IQR), while categorical variables are } \\
\text { defined as } n(\%) \text {. } \\
\text { PSQI: Pittsburg Sleep Quality Index; BMI: body mass index; HRT: hor- } \\
\text { mone replacement treatment; DM: diabetes mellitus; HT: hyperten- } \\
\text { sion; IQR: interquartile range }\end{array}$} \\
\hline
\end{tabular}

While 23 patients did not accept PSG evaluation, further PSG analysis was performed in 17 of the women with poor sleep quality. Among these, 6 (35.3\%) had normal and 11 (64.7\%) had abnormal results in the PSG evaluation. Mean PSQI score of women with normal PSG evaluation was $12.00 \pm 3.16$, while the mean score was $11.00 \pm 2.32$ in women with abnormal PSG evaluation, thereby revealing no statistically significant difference $(\mathrm{p}=0.466)$.

Eleven (64.7\%) women with abnormal results in PSG evaluation were diagnosed with OSAS. They were categorized as mild $(54.5 \% ; \mathrm{n}=6)$, moderate $(27.3 \% ; \mathrm{n}=3)$, and severe $(18.2 \% ; \mathrm{n}=2)$ OSAS based on the AHI levels.

\section{Discussion}

Menopause is a physiological period in a woman's life, which occurs at the age of approximately $56.6 \pm 6$ years (8). Similarly, the mean age of menopausal women in our study was found to be $52.12 \pm 7.24$ years (range $=33-72$ years).

Because women in menopause experience a wide range of symptoms as hot flashes, night sweats, mood changes, and sleep problems, sleep difficulties in a midlife women can easily be attributed to menopausal transition and/or menopause, in particular (9).

One of the most common sleep problems seen in menopause is insomnia with a prevalence of $28 \%-63 \%$, which includes difficulty in falling asleep and/or maintaining sleep, leading to daytime sleepiness and fatigue (10). The most frequent underlying causes of insomnia in menopause include anxiety, hot flashes, sleep-disordered breathing (sleep apnea), and restless leg syndrome (rhythmic limb movements) (3).

A US community-based survey demonstrated that $38 \%$ of the women between the ages of 40 and 55 years were suffering from sleep difficulty, and these rates were higher in the late perimenopausal and postmenopausal groups as $45.4 \%$, and $47.6 \%$, respectively (11). Suggesting the frequency of sleep problems in women with menopause, $59.7 \%$ of our study group was dealing with sleep problems, which were detected as poor sleepers because of the results of PSQI. We attributed the higher rate to the design of our study, which was held in the outpatient clinics of Gynecology and Obstetrics.

To confirm subjective sleep problems that we detected by PSQI and diagnose the possible underlying sleep-disordered breathing problems, we applied PSG evaluation to the patients with poor sleep quality who approved to undergo PSG evaluation; $64.7 \%$ of the patients had abnormal results and were diagnosed with OSAS. However, the lack of a control group can be considered as the limitation of our study.

Suggesting our results, previous studies have shown that the frequency and severity of sleep apnea increases during menopause because of weight gain and decrease in estrogen and progesterone levels $(12,13)$. Moreover, a previous report revealed that approximately $75 \%$ of the patients with OSA are suffering from obesity. Thus, obesity (BMI of $>30 \mathrm{~kg} / \mathrm{m}^{2}$ ) is a risk factor for OSA. Because obese people have large fat deposits in the neck, they are more likely to experience upper airway collapse in the supine position during sleep (14). However, the mean BMI of our participants was found to be $29.43 \pm 4.81 \mathrm{~kg} /$ $\mathrm{m}^{2}$ (range $=17.63-41.91$ ), but no statistically significant difference was found in the mean BMI of women with normal and abnormal PSQI scores.

Our PSG evaluation results revealed that the rate of moderate and severe OSAS was $45.5 \%$, which was higher than that in the study that determined the prevalence of moderate to severe insomnia as $20 \%$ (14). However, the study population, mean age, and menopause duration may be responsible for varying results.

A previous cohort study held in US revealed that menopause is the most important factor for reported sleep problems, in which the risk of sleep problems increase up to $1.2,1.3$, and 1.6 times in natural menopause, late perimenopause, and surgical menopause, respectively (11). Similarly, reported sleep problems based on our poor scores in the PSQI were higher in women with natural and surgical menopause being $60.5 \%$, and $58.3 \%$, respectively.

Because sleep problems are commonly reported complaints in women of peri- and postmenopausal period with varying underlying causes of mood changes to climacteric vasomotor symptoms, sleep-disordered breathing, and accompanying illnesses $(15,16)$, it is important to detect and treat sleep problems to increase the quality of life of women in menopause because there seems to be a higher frequency of sleep breathing problems in women with menopause. In this aspect, using 
PSQI and PSG evaluations would give a chance to demonstrate sleep problems and lighten the treatment options according to the underlying causes of sleep disturbances in menopause.

Ethics Committee Approval: Ethics committee approval was received for this study from the Local ethics committee of Düzce University Faculty of Medicine (2013/453).

Informed Consent: Written informed consent was obtained from patients who participated in this study.

Peer-review: Externally peer-reviewed.

Author Contributions: Concept - R.Ö., Y.D., M.Ç.; Design - R.Ö., M.C., E.G.B.; Supervision - R.Ö, M.Ç, E.G.B., A.B.; Resource - M.Ç., A.B., K.A.; Materials - M.Ç., A.B., K.A., M.A.S.; Data Collection and/or Processing M.C.., A.B., E.G.B., K.A.; Analysis and/or Interpretation - M.A.S.; Literature Search - K.A.; Writing - R.Ö., Y.D., M.Ç,. E.G.B., M.A.S

Conflict of Interest: No conflict of interest was declared by the authors.

Financial Disclosure: The authors declared that this study has received no financial support.

\section{References}

1. World Health Organization. Research on the Menopause in the 1990s. Technical report Scr. 1996; 866: Geneva, Switzerland.

2. McKinlay SM, Brambilla DJ, Posner JG. The normal menopause transition. Maturitas 1992; 14: 103-15. [CrossRef]

3. Freedman RR. Menopause and sleep. Menopause 2014; 21: 534-5. [CrossRef]

4. Chasens ER, Twerski SR, Yang K, Umlauf MG. Sleepiness and health in midlife women: results of the National Sleep Foundation's 2007 Sleep in America poll. Behav Sleep Med 2010; 8: 157-71. [CrossRef]

5. Gracia CR, Sammel MD, Freeman EW, Lin H, Langan E, Kapoor S, Nelson DB. Defining menopause status: creation of new definition to identify the early changes of the menopausal transition. Menopause 2005; 12: 128-35. [CrossRef]
6. Buysse DJ, Reynolds CF 3rd, Monk TH, Berman SR, Kupfer DJ. The Pittsburgh Sleep Quality Index: a new instrument for psychiatric practice and research. Psychiatry Res 1989; 28: 193-213. [CrossRef]

7. Berry RB, Budhiraja R, Gottlieb DJ, Gozal D, Iber C, Kapur VK, et al. Rules for scoring respiratory events in sleep: update of the 2007 AASM Manual for the Scoring of Sleep and Associated Events. Deliberations of the Sleep Apnea Definitions Task Force of the American Academy of Sleep Medicine. J Clin Sleep Med 2012; 8: 597-619.

8. Anagnostis P, Stevenson JC, Crook D, Johnston DG, Godsland IF. Effects of menopause, gender and age on lipids and high-density lipoprotein cholesterol subfractions. Maturitas 2015; 81: 62-8. [CrossRef]

9. Minarik PA. Sleep disturbance in midlife women. J Obstet Gynecol Neonatal Nurs 2009; 38: 333-43. [CrossRef]

10. Hachul H, Bittencourt LRA, Soares JM Jr, Tufik S, Baracat EC. Sleep in post-menopausal women: differences between early and late post-menopause. Eur J Obstet Gynecol Reprod Biol 2009; 145: 81-4. [CrossRef]

11. Kravitz HM, Ganz PA, Bromberger J, Powell LH, Sutton-Tyrrell K, Meyer PM. Sleep difficulty in women at midlife: a community survey of sleep and the menopausal transition. Menopause 2003; 10: 19-28. [CrossRef]

12. Eichling PS, Sahni J. Menopause related sleep disorders. J Clin Sleep Med 2005; 1: 291-300.

13. Joffe H, Massler A, Sharkey KM. Evaluation and management of sleep disturbance during the menopause transition. Semin Reprod Med 2010; 28: 404-421. [CrossRef]

14. Health Quality Ontario. Polysomnography in patients with obstructive sleep apnea: an evidence-based analysis. Ont Health Technol Assess Ser 2006; 6: 1-38.

15. Yazdi Z, Sadeghniiat-Haghighi K, Ziaee A, Elmizadeh K, Ziaeeha M. Influence of sleep disturbances on quality of life of Iranian menopausal women. Psychiatry J 2013; 2013: 907068. [CrossRef]

16. Timur S, Sahin NH. Effects of sleep disturbance on the quality of life of Turkish menopausal women: a population-based study. Maturitas 2009; 64: 177-81. [CrossRef] 